\title{
Exploring Best Practices for Client Satisfaction in the Saudi Construction Industry
}

\author{
Author Name: Fawaz Alshihre \\ Author Name: Dr Ezeliel Chinyio
}

\begin{abstract}
Customer satisfaction is the goal as well as the essential tool for measuring the quality and effectiveness of the construction industry. This paper aims to explore best practices that can be used by the Saudi Construction industry. For this purpose, the prevailing practices for client satisfaction followed in Saudi construction industry have been examined and compared with the best practices in the UK to identify the shortcomings and explore effective methods that can be used by Saudi constructors to provide enhanced client satisfaction. The data for this study has been gathered with the help of qualitative gathered from authentic secondary sources like books; peer-reviewed journals, construction reports and academic publications on construction and client satisfaction. Qualitative research methods involving interpretive paradigm, descriptive design and inductive approach have been used. The analysis of the findings has been done with the help of thematic analysis. The findings of the paper have revealed that Keywords- Client satisfaction, Saudi Arabian construction industry, UK construction industry time and cost management
\end{abstract}

\section{INTRODUCTION}

In an increasingly competitive and globalised economic environment, all companies have become customer oriented to maintain their sustainability and profitability in the market. Client satisfaction is the modern approach to surviving in the competitive market and a key determinant of the quality and effectiveness of the services offered by the organisation. It serves as the fundamental standard of excellence for any business organisation (Omonori and Lawal, 2014). The construction industry is a specific industry that has distinct attributes like, restricted location, temporary partnerships with firms and one-off projects. Due to such complicated nature of construction along with the specific features of the project production, construction industry encounters numerous problems while attempting to deliver maximum quality and satisfaction to the customer (Ali, Al-Sulhaili and Al-Gahtani, 2013).

Fawaz Alshihre, PhD Researcher

School of Architecture and Built Environment (FSE)

University of Wolverhampton

Supervisor Dr Chinyio, Ezekiel A.
Client satisfaction is the function of the extent to which the perceived quality of the customer is able or unable to fulfil the expectations of the customers. Satisfaction indicates the degree to which an organisation has been successful in meeting the needs and requirements of the customers. Client satisfaction is also has a direct relation to the relationship with the customers and quality of the construction process (Omonori and Lawal, 2014). While measuring the quality of construction, client satisfaction serves as the benchmark that helps in determining the keep shortcomings in the expected and the received quality. The examination of the literature on client satisfaction has revealed that the complicated nature of the construction industry increases the difficulties encountered by the contractors in delivering maximum satisfaction to the customers. In addition to that, external factors such as slow economic growth and high competition have put additional pressure on the construction companies to undertake continuous improvement in their productivity and performance so that maximum satisfaction can be delivered to the client (Ali, AlSulhaili and Al-Gahtani, 2013).

In this regard, the following research paper has examined the key issues and practices in the Saudi construction industry and compared them with the prevailing practices in the UK to determine the shortcomings in the Saudi construction industry and explore best practices that can be adopted to enhance client satisfaction.

\section{BACKGROUND}

The construction sector in Saudi Arabia is the largest and the fastest growing market in the Middle East region. There have been some factors such as growing economy, improving technology and continued support from the government that have led to the success and growth of the Saudi Arabian construction industry. The current value of existing contracts undertaken by Saudi Arabian construction industry has been $\$ 36.5$ billion in 2011, and the projected growth rate has been estimated to be $35 \%$ per annum (Kingdom of Saudi Arabia country report, 2013). In the last few years, construction projects worth $\$ 61$ billion have been awarded to the Kingdom. The construction industry 
contributes to the economic growth and development of the country to a large extent. The construction sector contributes about $8 \%$ to the total GDP of the country with a nominal CAD of $\$ 48$ billion every year (Canadian Trade Commissioner Service, 2014). The construction sector has been growing because of the heavy inflows of capital because of oil exports along with the opportunities for foreign investments in the country.

The need for commercial and residential infrastructure has further increased the prospects of growth for the Saudi construction industry. In addition, to that, the continuing investment in the developing infrastructure has also led to the boom in the Saudi construction industry. Each of these events has opened numerous opportunities for the growth and expansion of the construction industry in the Kingdom (Husein, 2014). These opportunities include the development of successful ventures of the Saudi construction companies with French, Italian and British construction companies. The active support and rigorous initiatives taken by the government of the Saudi Arabia for the growth of the infrastructure has provided impetus to the development of the construction sector (Saudi construction market analysis, 2014). It has also been examined from the literature that the Saudi construction industry is successful in holding a strong position with a high rate of success. Private and public construction agencies have largely contributed to the success of the profitability of the construction industry.

However, despite the success of the construction companies in the Kingdom, there have been numerous social, economic and technical factors that create pertinent hindrances in their global growth and success. These challenges create a serious impact on the level of satisfaction that can be delivered to the client. Client satisfaction has been the major issue in Saudi Arabian construction industry because of the complicated activities, problems related to skilled labour, advanced technology, time constraints, capital investment and market fluctuations (Rowlinson, 2004). These challenges prevent the contractors in delivering the project on the stated time and the given cost. The examination of literature has revealed that the contractors face rigorous problems and difficulties in meeting the expectations of the customers in respect of costs overrun, time delays and inappropriate quality (Langford and Male 2008).

Quality has been examined to be one of the major issues which indicates the failure in the effectiveness of the projects and eventually leads to failure of the construction companies in providing client satisfaction. The construction projects in Saudi Arabia are less efficient regarding design; specification costs management and quality standards in comparison with other countries. The rules and the regulations for the construction companies are also not strict in Saudi Arabia, which can be identified as the chief cause for the inappropriate quality in comparison to other countries (Wilson 2004). Therefore, client satisfaction is a major concern in the Saudi Arabian construction industry, and there is a need to explore best practices to overcome the prevailing problems and provide maximum satisfaction to the customers.

\section{AIM AND OBJECTIVES}

The main aim of the paper is to explore the practices that can be adopted by the contractors and project managers in the Saud Arabian construction industry to enhance client satisfaction by managing cost, time and quality in an effective manner. In this regard, the paper has compared the prevailing practices for construction management in the Saudi Arabian industry with the best practices in the construction industry of the UK to determine the shortcoming in the Saudi construction practices and explore effective and useful recommendations. To address this research aim, the following objectives have been developed:

- To critically examine the research conducted in the past on the construction industry to gain insight into the persisting issues and practices in the construction industry

- To examine the factors socio-cultural, economic, and technical factors that influence the practices and processes adopted by contractors and construction companies operating in Saudi Arabian construction industry

To compare and contrast the prevailing practices in the Saudi construction industry with the strategies followed by the UK to identify the best practices that should be adopted to provide best practices to client satisfaction

- To explore suitable recommendations as practices that can be adopted by Saudi Arabian construction industry to provide improved satisfaction to the clients 


\section{Review Methodology}

This research has used qualitative methods to develop effective and useful findings. In this regard, the interpretive paradigm has been used because it has allowed use of secondary sources to address the research objectives about client satisfaction in the Saudi Arabian construction industry. This paradigm has been useful for this paper because it allowed detailed examination of the research problem with the help of in-depth observation and study of the prevailing information and theories on client satisfaction in the construction industry (Belk, 2007). The paper has used descriptive design in combination with interpretive paradigm because it is helpful in gathering, analysing and interpreting information about client satisfaction and the key factors associated with the construction industry. Further, being based on secondary and qualitative methods, descriptive methods have served to be helpful in studying the problems encountered by Saudi contractors and the exploring the best practices that can help them in providing maximum client satisfaction.

The use of descriptive design has also served as a significant foundation to test the gathered theoretical data on client satisfaction (Supino and Borer, 2012). The descriptive design has been made effective by combining it with inductive research approach. This approach has been used because this study moves from specific (client satisfaction in the construction industry) to general (factors associated with client satisfaction). This approach has been useful because in providing a specific direction to the information in the paper has helped in obtaining logical conclusion (Taylor, Kermode and Roberts, 2006). This approach is also in alignment with the interpretive paradigm and qualitative method that has helped in enhancing the credibility, reliability and validity of the findings (Pathirage, Amaratunga and Haigh, 2008). To further ensure the authenticity and integrity of the data collected all efforts were made to gather authentic data from reliable and latest academic sources. The data for the study has been gathered from secondary sources that included books, journals, academic publication and reports on construction industry of Saudi Arabia. Appropriate articles were shortlisted with the help of exclusion and inclusion criteria. Under the inclusion criteria, the keywords were used while exclusion criteria involved the keywords that were not used in the study (Axinn and Pearce, 2006).

Secondary data is very useful while undertaking an in-depth critical analysis of the research problem. It also helps in gathering and analysing the perspectives and perceptions of a wide range of academicians and scholars about the research subject. The data collected with the help of secondary sources helped in providing a strong conceptual foundation to the study. To overcome the problem of outdated data, it was ensured that the data has been gathered carefully and cautiously used to address the research objectives (Gratton and Jones 2010). The gathered data was studied with the help of literature review and analysed with the help of thematic analysis and overall findings and results were derived to address the objectives (Walsh and Wigens, 2003).

\section{LITERATURE REVIEW}

The construction industry of Saudi Arabia is showcasing a positive trend as a compound annual growth rate (CAGR) of $10.06 \%$ was recorded for the year 2009-2013. There are several factors that will contribute to the growth of the construction industry in Saudi Arabia such as the increase in population, lack of housing facilities and unavailability of transport network (PRNewswire, 2014). In this regard, the literature review is conducted further in order to explore various aspects related to the level of customer satisfaction in the construction industry of Saudi Arabia.

\section{a. Issues in Saudi Construction Industry}

In the opinion of Azis et al. (2012), the construction industry is often faced with different types of financial, technological, human resource and operational issues. The overrunning of cost often contributes towards financial issues, whereas, the malfunctioning of technical equipment often contributes towards the technological issues in the construction industry. In addition to this, the poor management of waste also acts as a serious problem for the construction companies as increasing waste tend to add up to the extra cost of the construction (Azis et al., 2012).

In the opinion of Alrashed et al. (2014), the different types of operational risks are faced by the construction companies due to prolongation of the project duration and structural complication. Furthermore, the literature also indicates that due to poor knowledge and less awareness, the construction companies lack an adequate risk management system to deal with the operational risks. The limited knowledge also acts as a challenge for the construction companies to formulate an effective risk management system (Alrashed et al., 2014). 


\section{b. Need For Client Satisfaction in Saudi Construction Industry}

In the opinion of Costa et al. (2006), client satisfaction is essential for the construction company as its key objective upon which the key business decisions and work efficiency are dependent. It is also indicated from the literature that the higher focus on the customer satisfaction helps the company in maintaining and enriching its relationship with stakeholders, especially its clients. Furthermore, if the construction company has a brand name and satisfied clients, there is less chance of it having conflicts and disputes with the customers. The objective of client satisfaction often bridges the gap between the customer and the company, thereby, promoting superior work quality and the establishment of mutual trust (Costa et al., 2006).

In the opinion of Ali, Al-Sulaihi, and AlGahtani (2013), customer satisfaction is an essential factor that directly co-relates with the productivity and performance of the construction companies. In order to attain a unique competitive advantage, many construction companies of Saudi Arabia include client satisfaction as the core aim of their businesses. Furthermore, greater the level of client satisfaction for the performance of the construction companies, higher is their chances of sustainability in the slow economic market of Saudi Arabia (Ali, Al-Sulaihi, and Al-Gahtani, 2013).

\section{c. Practices Followed By the Contractors In Saudi Construction Industry For Client Satisfaction}

According to Dikmen, Birgonul and Kiziltas (2005), the construction companies of Saudi Arabia are adopting various quality maintenance techniques to attain a high degree of client satisfaction. As per the literature, the construction companies are inclining towards practices like total quality management and quality functional deployment in order to ensure that different construction processes are carried out with the highest quality standard as prescribed in the client's requirements. The quality management techniques are not only boosting the level of satisfaction in clients but also playing a key role in improving the brand image of the construction companies (Dikmen, Birgonul and Kiziltas, 2005).

In the opinion of Ayman, Tarek and Christine (2005), the construction companies are also using the concept of dynamic brief development in order to facilitate the project changes through the life of the project. This technique is adopted by the construction companies to determine and evaluate the current loopholes in the project in terms of the design and techniques and to improve the project to suit with client requirements (Ayman, Tarek and Christine, 2005).

\section{d. Overview of the Construction Industry in the UK}

According to Sorrell (2001), the current construction industry of the UK has seen a downfall trend, and the reasons for the slow pace of the industry are inadequate material procurement, blind faith on cost based tendering and linear designing processes. Furthermore, the literature indicates that the poor research and development, high competition and low investment support also result in the downfall of the construction industry in the UK. It is also determined that poor policies that have been formulated on the basis of conventional engineering also negatively affect the construction projects of UK (Sorrell, 2001).

\section{e. Comparison between the Construction Industries in the UK and Saudi Arabia}

In the opinion of Abdul-Hadi, AL-Sudairi and ALQahtani (2004), the construction companies of Saudi Arabia use more traditional techniques such as business project re-engineering (BPR) for their construction projects, whereas, in the UK, the construction companies implement modern and advanced technology for the effective execution of the construction projects.

Furthermore, the evaluation of construction contracts in the UK is entirely based on cost, whereas, in Saudi Arabia, other factors such as project duration, design and contract type are also considered. In addition to this, there is a high number of skilled workforce present in the UK in comparison with the construction industry of Saudi Arabia, which is constantly focused on providing innovative construction solutions for higher satisfaction of their clients (Abdul-Hadi, ALSudairi and AL-Qahtani, 2004).

\section{f. Ways in which Saudi Construction Industry Improve Client Satisfaction by Adopting Practices Followed}




\section{in the UK Construction Industry}

In the opinion of Alotaibi, Yusoff and Islam (2013), there are several ways that can be implemented by Saudi construction industry by adopting the practices followed in the UK construction industry in order to enhance their brand value, profitability and overall client satisfaction. The literature indicates that the Saudi Arabia's construction companies should focus on adopting customer-centric project management tools and strategic data management system. Furthermore, they should use various measures of improvement such as collaborative working, total quality management, feedback system and networking and scheduling techniques in order to facilitate effectiveness and efficiency in the construction projects (Alotaibi, Yusoff and Islam, 2013).

\section{FINDINGS \\ AND CONCLUSION}

By the examination of the overall literature and evaluation of the articles, it is found that the construction industry in Saudi Arabia encounters some challenges related to technology, finance, operations and human resource. In this regard, cost overruns, inappropriate understanding of the advanced technology and absence of skilled technical labour along with poor waste management practices are the major challenges that prevent the construction companies in meeting the time deadlines and managing cost overruns (Alotaibi, Yusoff and Islam, 2013). It has also been found that the in comparison to the construction industries in Saudi Arabia, the UK construction industry makes use of advanced technology and skilled manpower to improve the success of the projects. For this purpose, the companies use strategic data management systems and project management tools which help them in obtaining customer-centric results (Al-Yami and Price, 2006). In this respect, it has been examined and concluded that the use of demand diverse project management techniques, collaborative working, feedback system, total quality management and effective networking and scheduling techniques can be helpful for Saudi contractors in providing maximum client satisfaction (Karna and Junnonen, n.d.).

\section{ACKNOWLEDGEMENT}

I would like to express my sincere gratitude to my supervisor for his effective guidance and direction and helping me make this scientific paper a success. I would also like to thank my faculty members who provide useful suggestions and helped me writing the paper in an efficient manner. I would also thank my friends and family members for their support and encouragement while writing the paper.

\section{REFERENCES}

1) Ali, H.A.E.M., Al-Sulhaili, I. and AlGahtani, K. 2013. Indicators or measuring performance of building construction companies in Kingdom of Saudi Arabia. Journal of King Saud unidersity 25, pp. 125-134.

2) Alotaibi, F., Yusoff, R.J and Islam, R. 2013. Assessing the impact of total quality management practices and quality culture with competitiveness of Saudi contractors. American Journal of Applied Sciences 10 (6), pp. 638-645.

3) Al-Yami, A.M. and Price, A.D.F. 2006. A framework for implementing sustainable construction in building briefing project. Association of Researchers in Construction Management, pp. 327-337.

4) Axinn, W.G, and Pearce, L.D. 2006. Mixed method data collection strategies. Cambridge University Press.

5) Belk, R.W. 2007. Handbook of Qualitative Research Methods in Marketing. Massachusetts: Edward Elgar Publishing.

6) Canadian Trade Commissioner Service. 2014. [Online]. Available at: http://www.enterprisecanadanetwork.ca/_u ploads/resources/Construction-SectorProfile-Saudi-Arabia.pdf. [Accessed on: 05 January 2016].

7) Gratton, C., and Jones, I. 2010. Research Methods for Sports Studies. Taylor \& Francis

8) Husein, A.T. 2014. Construction and projects in Saudi Arabia: Overview. [Online]. Available at: www.dentons.com/ /media/PDFs/Insights /.../Saudi\%20Arabiapdf.pdf. [Accessed on: 05 January 2016].

9) Karna, S., Junnonen, J.M. and Kankainen, J. n.d. Customer satisfaction in 
construction. [Online] Available at: http://www.cem.tkk.fi/fsr/Propal/manage ment/Customer\%20satisfaction\%20in\%20 construction.pdf. [Accessed on: 05 January 2016].

10) Kingdom of Saudi Arabia country report. 2013. [Online]. Available at: https://www.bca.gov.sg/ExportServices/ot hers/KSACountryReport.pdf [Accessed on: 05 January 2016].

11) Langford, D. and Male, S. 2008. Strategic Management in Construction $2^{\text {nd }} e d$. Malden: John Wiley \& Sons.

12) Omonori, A. and Lawal, A. 2014. Understanding customer's satisfaction in construction industry in Nigeria. Journal of Economics and Sustainable Development 5(25), pp. 115-120.

13) Pathirage, C.P., Amaratunga, R.D.G. and Haigh, R.P. 2008. The role of philosophical context in the development of theory: Towards methodological pluralism. The Build \& Human Environmental Review, 1, pp. 1-10.

14) Rowlinson, S. 2004. Construction Safety Management Systems. New York: Taylor \& Francis

15) Saudi construction market analysis. 2014. [Online]. Available at: http://www.constructarabia.com/thebig5/saudi-construction-market-analysis/ [Accessed on: 05 January 2016].

16) Supino, P.G. and Borer, J.S. 2012. Principles of Research Methodology: A Guide for Clinical Investigators. Springer.

17) Taylor, B.J. Kermode, S. and Roberts, K.L. 2006. Research in Nursing and Health Care: $\quad$ Evidence for Practice. Cengage Learning Australia.

18) Walsh, M. and Wigens, L. 2003. Introduction to Research. Nelson Thornes.

19) Wilson, R. 2004. Economic Development in Saudi Arabia. Location: Routledge.

20) Alrashed, I. et al. 2014.Risk Assessments for Construction projects in Saudi Arabia. Research Sciences. 3(7), pp. 1-6

21) Azis A. A. A. et al., 2012. Challenges faced by construction industry in accomplishing sustainable goals. [Online] Available at: http://www.researchgate.net/profile/Aftab _Memon/publication/258224425_Challen ges_faced_By_Construction_Industry_in_ Accomplishing_Sustainablity_Goals/links/ 00463533e567b1edab000000.pdf. [Accessed on: 5 January 2016].

22) Alrashed, I., Alrashed, A., Taj, S., and Kantamaneni, K. 2014. Risk Assessments for Construction projects in Saudi Arabia. Research Journal of Management Sciences 3(7), pp.1-6.

23) Ali, H.A.E.M., Al-Sulaihi, I.A., AlGahtani, K.S. 2013. Indicators for measuring performance of building construction companies in Kingdom of Saudi Arabia. Journal of King Saud University - Engineering Sciences. 25(2), pp. 125-134.

24) Ayman, A.E., Tarek, M.H. and Christine, L.P. 2005. Analysis of factors that drive brief development in construction. Engineering, Construction and Architectural Management 12(1), pp. 6987.

25) Abdul-Hadi, N., AL-Sudairi, A. and ALqahtani, C. 2004. Prioritizing barriers to successful business process reengineering (BPR) efforts in Saudi Arabian construction industry.

Construction Management and Economics 23, pp. 305-315.

26) Alotaibi, F., Yusoff, R.J and Islam, R. 2013. Assessing the impact of total quality management practices and quality culture with competitiveness of Saudi contractors. American Journal of Applied Sciences 10 (6), pp. 638-645.

27) Costa, D., Formoso, C., Kagioglou, M., Alarcón, L. and Caldas, C. 2006. Benchmarking Initiatives in the Construction Industry: Lessons Learned and Improvement Opportunities. Journal of Management in Engineering, pp. 158166.

28) Dikmen, I., Birgonul, M.T. and Kiziltas, S. 2005. Strategic use of quality function deployment (QFD) in the construction industry. Building and Environment 40, pp. 245-255.

29) PRNewswire. 2014. Saudi Arabia Construction Industry: 10.98\% CAGR Forecast to 2018. [Online]. Available at: http://www.prnewswire.com/newsreleases/saudi-arabia-constructionindustry-1098-cagr-forecast-to-2018285917141.html. [Accessed: 5 January, 2016].

30) Sorrel, S. 2001. Making the Link: Climate Policy and the Reform of the UK Construction Industry. Science and Technology Policy Research. 